\title{
Para una crítica epistemológica de la praxiología motriz
}

\author{
Towards an Epistemological Critique of Motor Praxeology \\ RAÚL SÁNCHEZ GARCÍA \\ Universidad Europea de Madrid
}

Correspondencia con autor

Raúl Sánchez García

raul.sanchez@uem.es

\begin{abstract}
Resumen
Este artículo pretende establecer una crítica epistemológica de la disciplina científica desarrollada por Pierre Parlebas: la praxiología motriz. Principalmente se dedica a señalar las limitaciones que encuentra esta en la delimitación del objeto estudio (la acción motriz), considerado fundamental en las actividades físico deportivas. La ausencia en sus análisis de una temporalidad propia de los cursos de acción en las prácticas va a ser el principal obstáculo para una caracterización adecuada de tales actividades. Esta circunstancia va a revertir además en una concepción limitada de la capacidad de agencia de los participantes y de la racionalidad práctica de los mismos. Todo ello afectará además a sus posibles vías de aplicación (por ejemplo, en el diseño pedagógico). Como posible solución a tales deficiencias se propondrá una vuelta al análisis de los cursos de acción del juego tal y como plantea la etnometodología.
\end{abstract}

Palabras clave: praxiología, temporalidad, agencia, sentido de juego, etnometodología

\section{Abstract \\ Towards an Epistemological Critique of Motor Praxeology}

This article seeks to establish an epistemological critique of the scientific discipline developed by Pierre Parlebas: motor praxeology. It mainly sets out the limitations of the latter in the definition of the object of study (motor action), considered fundamental in sport and physical activities. The absence in its analysis of the time of the courses of action in practice is the main obstacle to a proper description of these activities. This circumstance will also lead to a narrow conception of the participants' capacity to act and their practical rationality. This will also affect its possible applications (for example, in instructional design). A return to the ethnomethodology approach to analysis of courses of action in games is put forward as a possible solution to such shortcomings.

Keywords: praxiology, time, capacity to act, course of action in games, ethnomethodology

\section{Introducción}

Evidentemente, la modelización de las situaciones motrices no es un método milagroso; suscita también problemas epistemológicos de difícil solución, como la posible reducción y empobrecimiento de la realidad observada, la adopción de un punto de vista inicial con una orientación demasiado marcada, la transferencia indebida del modelo de un campo a otro, cuestiones de análisis conceptual... (Parlebas, 2001, p. 340).

Mi primer encuentro con la praxiología motriz, desarrollada por Pierre Parlebas, surgió a lo largo de la realización de una investigación empírica que formaba parte de mi tesis doctoral (Sánchez, 2006). Pretendía en esta poner en relación los distintos deportes de combate existentes en nuestro país con niveles de violencia. Encontré en la obra de Parlebas (2003) una aproximación específica a este ámbito desde la perspectiva praxiológica, algo que prometía un sistema de clasificación bastante coherente a primera vista. Pronto descubrí que, en este caso, la célebre inversión de Marx acerca de no confundir las cosas de la lógica con la lógica de las $\cos a s,{ }^{1}$ cobraba toda su fuerza y que más que ayudar y clarificar la situación, el enfoque praxiológico debía ser abandonado si pretendía dar cuenta de las evidencias

\footnotetext{
1 O, como indica Bourdieu de forma más elaborada: "Una de las contradicciones prácticas del análisis científico de una lógica práctica reside en el hecho paradójico de que el modelo más coherente y también el más económico, el que explica de la manera más simple y sistemática el conjunto de hechos observados, no es el principio de esas prácticas...” (1991, p. 30).
} 


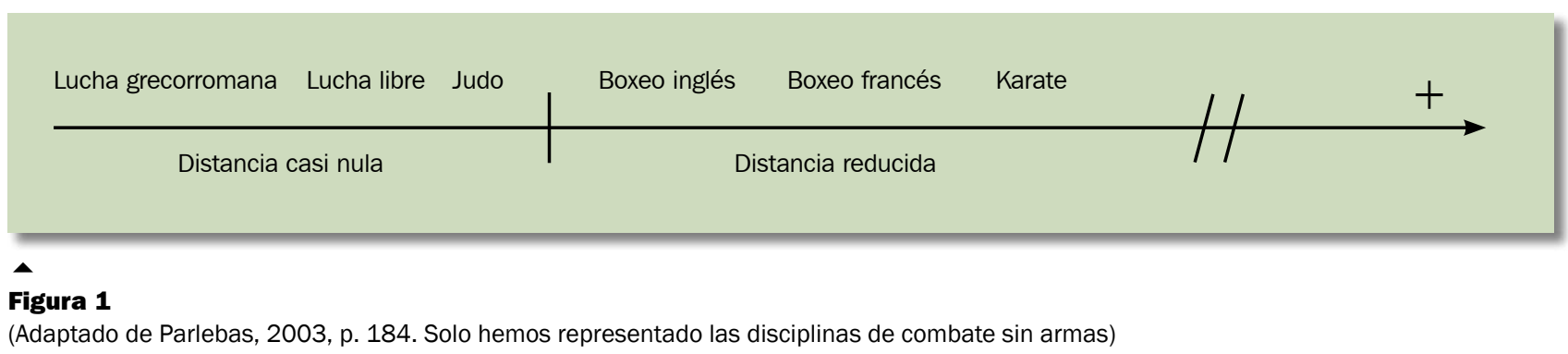

empíricas que encontraba en mi investigación. Podemos decir por tanto que la crítica epistemológica de la praxiología no partió desde un análisis del entramado teórico praxiológico -eso vendría después- sino de la inadecuación que tal enfoque presentaba ante la experiencia y que me hizo ser más sensible a las posibles limitaciones de esta disciplina científica. Veamos brevemente en qué consistía el ejemplo del cual partió todo.

Comencemos prestando atención al análisis de los denominados deportes de combate que realiza Parlebas (2001, 2003). Según este autor, un factor fundamental de los deportes de combate que condiciona su lógica interna y su relación con el manejo de la violencia es el de "distancia de enfrentamiento motor" (2003, pp. 182 y ss., aunque también, 2001, pp. 150 y ss.), que para duelos individuales -los que ocupan nuestra atención- se identifica con la "distancia de guardia". Podemos diferenciar:

- Duelos a distancia casi nula, de menos de un metro: lucha o judo, por ejemplo.

- Duelos a distancia reducida, de uno a tres metros: boxeo, boxeo francés, ${ }^{2}$ karate.

- Duelos a distancia media, de tres a cinco metros: esgrima.

- Duelos a gran distancia, de más de cinco metros: deportes de raqueta.

Parlebas va a relacionar esta "distancia de guardia" con el concepto de "espacio individual de interacción" (2003, pp. 187 y ss.), que es la superficie obtenida al dividir el terreno de juego entre el número de jugadores. Según este autor, refiriéndose a los duelos individuales (a los que pertenecen las disciplinas de combate), "el espacio individual de interacción aumenta en el mismo sentido que la distancia de guardia y que la violencia de los contactos"3 (2003, p. 188). Esto, aclara el autor, siempre que pongamos en relación deportes de una misma subcategoría de distancia de guardia (por ejemplo, aquellos de distancia casi nula), no tomando todos los deportes de combate de manera absoluta. Para ejemplificar estas conclusiones coloca a cada una de las disciplinas en una regleta referida a la distancia de guardia del modo que se detalla en la figura 1 .

Según esta clasificación, ¿deberíamos decir que el judo es más violento que las luchas? Y si esta apreciación es ya dudosa, ¿no lo es aún más considerar que el karate es más violento que las modalidades de boxeo? ¿No ocurre en la actualidad más bien lo contrario?

Creemos que tal confusión proviene de la necesidad del autor de adaptar la realidad de la práctica a sus esquemas clasificatorios. La relación de los términos "distancia de guardia" o "espacio individual de interacción" con los comportamientos violentos está planteada desde una óptica teórica de la acción; desde la generación de unos tipos ideales referidos a las actividades y de acuerdo al a priori estructuralista parlebasiano según el cual todas esas actividades se comportan conformando un sistema:

La distribución graduada de las distancias de enfrentamiento motor, ordenadas en el interior de cada categoría de prácticas e inversamente ordenadas de una categoría a otra, parece demostrar claramente que las especialidades deportivas funcionan como sistemas. Los valores reglamentados de estas distancias pueden considerarse, dentro de cada sistema, como un indicador de la violencia permitida (Parlebas, 2001, p. 151).

2 El boxeo francés o savate es una modalidad en la que se utilizan puños y piernas y se parece a disciplinas más conocidas como el full-contact o el kick-boxing.

3 Para justificar esta aseveración, Parlebas evoca un planteamiento físico extremadamente débil, a saber, que: “... coger carrerilla permite darse impulso, hacerse más contundente y eficaz" (2001, p. 151), algo que muestra un completo desconocimiento de la mecánica de este tipo de disciplinas. 
Tales tipos ideales no pueden dar cuenta además de la variación que encontramos entre prácticas con igual nombre pero no unitarias, que guardan tan sólo cierta relación de familiaridad. En mi tesis, por ejemplo, identifiqué al menos cuatro tipos de prácticas diferentes referidas al boxeo: profesional, amateur, recreativo y utilitario. Todas mantenían ciertas características identitarias afines pero también toda una serie de características distintivas que hacían variar de manera significativa los niveles de intensidad y violencia y la forma de afrontar y valorar el contacto físico en la actividad; factores todos ellos que desde el punto de vista de aplicación educativa son vitales. Es más, considerando esos diferentes tipos de prácticas en los deportes de combate en general, éstos eran más significativos que el nombre de la actividad en sí a la hora de determinar el grado de violencia física. Así por ejemplo, mientras el karate entendido como actividad deportiva aficionada era menos violento que el boxeo profesional, el karate practicado y utilizado como defensa personal, de manera utilitaria, podía ser mucho más violento que un tipo de boxeo recreativo. La praxiología no es que no las diferenciara -pudiendo alegar que se limitaba a caracterizar las modalidades más representativas, las de competiciones deportivas regladas en todos los casos-, es que no era capaz de diferenciarlas sin salir de unos criterios meramente praxiológicos: ${ }^{4}$ cogiendo el caso del boxeo, todos esos tipos distintos de actividades (profesional, amateur, recreativo, utilitario) pueden ser identificadas como boxeo; todas tienen características de interacción y de lógica interna muy parecidas, los grafos, los roles y subroles motores nada dirían sobre las diferencias de lo que allí ocurre y sin embargo decimos que la diferencia en la intención encarnada en los distintos tipos de una misma modalidad es fundamental para su caracterización y posible aplicación formativa.

A lo largo de este artículo pretendemos poner de relieve como es la inadecuada atención de la praxiología a lo que ocurre en los cursos de acción de las actividades ludodeportivas la principal limitación que encuentra a la hora de dar una caracterización pertinente de las mismas y de proponer aplicaciones de programas basados únicamente en sus resultados.

\section{Pretensión de la praxiología}

Pierre Parlebas se propuso como meta fundamental dar una entidad científica a lo que hasta ahora se conoce como un conglomerado de ciencias de la actividad física y deportiva (Parlebas, 1987; Lagardera, 1993). Este autor creía que debía encontrarse la disciplina rectora, propia de estos estudios, alrededor de la cual se articularan todas las demás. Trataba de encontrar la especificidad de este ámbito y creyó conseguirlo mediante el estudio de lo que va a considerar el objeto propio de tal disciplina: la acción motriz.

Para llevar a cabo este cometido decide apoyarse en la forma de proceder de la disciplina científica en ciencias sociales que en general -en Francia con especial fuerza- se había erigido como paradigmática: la lingüística estructuralista iniciada por Ferdinand de Saussure. Que toda la obra de Parlebas remite a los planteamientos de la lingüística y de su aplicación a otros ámbitos culturales -en cuyo caso encontramos la semiología o estudio de signos tal y como la utilizó Roland Barthes- es fácilmente constatable si uno analiza el opum mágnum de Parlebas (2001), el Léxico de praxiología motriz. Tanto es así que la praxiología perfectamente podría denominarse como "lingüística motriz" o "semiología motriz" -Parlebas da un trato prioritario a lo que denomina semiotricidad y afirma (2001, p. 124) que el praxiólogo es un semiotricista- si bien el autor trata de desmarcarse de estas disciplinas abogando por la especificidad de la actividad física respecto a esas manifestaciones simbólicas del lenguaje (Parlebas, 2001, p. 125). Otra cosa es que lo consiga; la actividad físico-deportiva aparece en la obra de Parlebas como un conjunto de signos (físicos, eso sí) que hay que codificar y descodificar, como un texto que tiene una gramática interna a partir de la cual realizan variaciones los individuos participantes que reproducen sin saberlo los patrones de esa lógica interna cuyo estudio es lo propio de la disciplina praxiológica. Parlebas, consciente de las limitaciones que podría tener tal orientación, trata de introducir una serie de conceptos de corte socio-histórico y psicológico (pertenecientes a la lógica externa) en un intento de abordar la dinámica y el cambio de los sistemas. En mi opinión no consigue

\footnotetext{
4 Parlebas (2001, pp. 170 y ss.) intenta dar cuenta de las posibles variaciones de práctica dentro de una disciplina con el mismo nombre, por ejemplo en el tipo de actividades que se hacen en la naturaleza y que Parlebas denomina ecojuegos -que, atendiendo a la situación ludomotriz, son casi juegos (2001, p. 52)- como surf, escalada, montañismo, etc., diciendo que se diferencian en varias características respecto a sus homónimos con un tipo de competiciones regladas, introduciendo el rasgo distintivo de la incertidumbre (en su clasificación CAI) muy presente en las primeras y más ausente en las segundas. Sin embargo, ¿cómo podría hacer una caracterización distintiva respecto a las prácticas de combate con un mismo nombre que son diferentes pero cuyos espacios de práctica son iguales, incluso cuando además encontramos practicantes mezclados como cuando en un mismo gimnasio de boxeo hay profesionales y aficionados?
} 
tal cometido y además se extralimita al tratar de utilizar sus descubrimientos sobre la lógica interna para esclarecer cuestiones de tipo social o pedagógico, tal y como veremos en el último apartado.

Vamos a trazar mediante diversos apartados el camino transitado por Parlebas a la hora de desarrollar su disciplina y ver así cómo en la construcción de su objeto científico precisamente pierde lo que es específico de las actividades físico-deportivas, a saber, la temporalidad propia de la práctica, lo que va a tener consecuencias muy significativas.

\section{La predominancia de la lógica interna}

El lenguaje es un sistema que tiene su propio acuerdo. La comparación con el ajedrez mostrará a qué nos referimos. En ajedrez, lo que es externo puede ser separado con relativa facilidad de lo que es interno. El hecho de que el juego pasara de Persia a Europa es externo; por el contrario, todo lo que tenga que ver con el sistema y las reglas es interno. Si uso piezas de marfil en vez de madera, el cambio no tiene efecto en el sistema; pero si disminuyo o incremento el número de piezas, este cambio tiene un profundo efecto en la "gramática" del juego (De Saussure, 2000, pp. 54-55).

La metáfora del juego de ajedrez que tanto usaba Saussure es perfecta para el objetivo de Parlebas de realizar la transición de las cuestiones del lenguaje a las físico-deportivas ${ }^{5}$ y encontrar así la especificidad de sus estudios. Parlebas parte de los supuestos de la lingüística sausseriana (con la distinción interno-externo) ${ }^{6}$ y cree que la actividad físico-deportiva puede descomponerse en una lógica interna -formal, profunda y subyacente-, una especie de gramática, en este caso de los juegos deportivos, y una lógica externa (subordinada a la interna) que tiene que ver con lo social, lo histórico, las características psicológicas de los participantes. Así por ejemplo introduce el término etnomotricidad para expresar las variables sociohistóricas de las actividades pero las relega al plano de meras variaciones de los universales, característicos de la lógica interna, que es lo verdade- ramente característico de la praxiología. Lo demás -lo externo- queda como objeto de diversas disciplinas que deben estar en diálogo con la propuesta praxiológica pero que no comparten sus mismos asuntos.

Partiendo del acto de privilegio de lo interno es como Parlebas trata los juegos deportivos como sistema organizados (estructurados) en los cuales podemos encontrar diversos elementos que son significativos en cuanto que tienen un valor, obtenido siempre en relación a otros elementos que conforman tal sistema. Son valores los roles y subroles de los que habla Parlebas (2001, pp. 399, 430) y nada tienen que decir sobre ellos los participantes que, simplemente pueden ofrecer variaciones ya instituidas en tales valores asociados a la lógica interna propia del juego.

Sin embargo, podemos objetar que tal entramado teórico está basado en un doble movimiento -de ida y vuelta- que conforma a la vez el núcleo principal y la incapacidad de la praxiología para tratar con pertinencia el ámbito de las actividades ludodeportivas; algo que nos proponemos mostrar a continuación.

\section{Un movimiento doble: pérdida de la temporalidad práctica}

La praxiología de Parlebas se cimienta en un doble movimiento de ida y vuelta. Parlebas parte de la observación de una serie de actividades ludodeportivas para, mediante la toma de distancia frente a las mismas, ser capaz de generar unos modelos científicos referidos a la gramática, la lógica interna de cada uno de los juegos observados. Para ello debe abandonar la temporalidad propia de los juegos y sumergirse en la temporalidad propia del análisis teórico, a saber, la atemporalidad, lo eterno y ahistórico, la estructura subyacente; es lo sincrónico lo que importa, no lo diacrónico. Hasta aquí, la pretensión científica de Parlebas es lícita. Como a menudo indica este autor, la creación de modelos no debe confundirse con la realidad tratada. Es de este modo como la praxiología puede ser utilizada de forma

\footnotetext{
5 Si bien Parlebas (2001, p. 86) no considera al ajedrez como situación motriz, sí utiliza el símil de Saussure en el desarrollo de su entramado conceptual.

6 Toda la lingüística sausseriana, y por ende la praxiología parlebasiana, se basa en una serie de pares confrontados (siendo el primero el elemento privilegiado), de los cuales la pareja langue-parole es la matriz principal. Atendiendo específicamente a Parlebas, podemos encontrar ejemplos de tales binomios en: lógica interna-lógica externa, conducta motriz-comportamiento motor, decisión motriz-percepción y ejecución, estrategiatáctica, (des)codificación-información, decisión libre-hábitos, consciencia-inconsciente motor, etc. Tal distribución atiende -muy a pesar de lo que dice pretender tal autor- a la separación clásica de toda la ontología occidental entre mente-cuerpo de la cual la praxiología es deudora. De hecho, la praxiología borra los cuerpos y la encarnación situada de los agentes porque lo considera como epifenómeno de lo objetivo-subyacenteinterno y causa fundamental de un enfoque de tipo no científico. Según el propio autor: "Continuar razonando en términos de cuerpo o de movimiento es regresar a las concepciones de antaño, a posiciones anticuadas y ambiguas...” (Lagardera \& Lavega, 2003, p. 8).
} 
eficaz como herramienta clasificatoria de los juegos mediante la generación y comparación de tipos ideales, relacionados con los criterios universales que definen las lógicas internas de cada actividad. Sin embargo, debemos ser cautos y no perder de vista que son solo eso, tipos ideales, y que, si bien sirven de aproximación a las prácticas concretas, no las contienen ni las cierran del todo. Este es el problema que encontramos cuando, con Parlebas, intentamos volver a la temporalidad propia de la práctica sin tener en cuenta la relación de su visión (distanciada y objetivada, de tipos ideales) respecto a la actividad. No queremos decir que Parlebas no tenga consciencia del concepto de temporalidad (ver Parlebas, 2001, p. 445) sino que lo relega al ámbito socioinstitucional -referido a la lógica externa- considerándola como algo que puede desligarse del propio análisis (interno) de las prácticas. Es así como introduce en esos cursos de acción una temporalidad ajena, que hace perder la pertinencia de las aspiraciones praxiológicas: después de haber descifrado el "esqueleto" o la lógica interna de las prácticas, lo traspone de nuevo a la actividad, considerando que tal lógica está comportada por una serie de reglas que los agentes no pueden más que seguir, ${ }^{7}$ siendo la variación una cuestión de estilo personal. Como veremos en el próximo apartado, esto va a tener unas consecuencias profundas a la hora de concebir la capacidad de agencia de los participantes.

Todo esto proviene de la confusión ejercida desde la separación de la lógica interna y externa en la cual parece que las actividades concretas de la práctica pertenecen a la lógica externa y por tanto deben ser consideradas como epifenómenos de la lógica interna subyacente. Es así como precisamente se pierde, se deja sin atender la temporalidad propia de la actividad, algo que solo puede evitarse estudiando específicamente los cursos de acción y encontrar la forma en que esos están estructurados, algo que no debe confundirse con lo que Parlebas identifica como estructura interna ya que pertenecen a dos ámbitos temporales distintos.

Tal confusión se debe a que Parlebas aboga por lo que podría considerarse como legalismo: confunde la actividad de los actores con las leyes que marcan y delimitan la actividad de los actores. Para aclarar este fenómeno deberíamos identificar al menos tres tipos distintos de reglas o leyes asociadas a la actividad humana:

1. Leyes científicas, como las que encontramos en matemáticas o física, las que Parlebas trata de instituir como universales.

2. Leyes normativas o jurídicas, las referidas a las reglas del juego.

3. Leyes entendidas como regularidades, como patrones recurrentes de actividad.

En sus análisis, Parlebas sólo presta atención a la primera (al hablar de la lógica interna de carácter formal) y a la segunda (al hablar de las reglas de los juegos), estableciendo una fuerte interrelación entre ambas: ciertos juegos con ciertas reglas tienen asociadas ciertas lógicas internas. Sin embargo, sobre el caso tres, Parlebas no presta gran atención y ahí precisamente se da la confusión. Tal error proviene de la atemporalidad de los supuestos praxiológicos: tanto en lo referido a $a$ ) la historicidad ${ }^{8}$ como a $b$ ) las acciones de juego o cursos de acción.

a) Parlebas parte del mito fundacional del contrato social de Rousseau aplicado a los juegos mediante el contrato ludomotor por el cual se establecen una serie de reglas que los participantes aceptan para poder realizar la actividad. Esta artificialidad es la excepción (por ejemplo en la creación de disciplinas modernas como el baloncesto o el voleibol) ya que la mayoría de juegos y deportes surgen a lo largo de mucho tiempo mediante prácticas lúdicas poco o casi nada pactadas (donde el límite entre juego-no juego no está nada claro) en las cuales se daban patrones más o menos recurrentes de acción que fueron acotándose mediante reglas para mejorar el disfrute de la práctica, tal y como indican Elias y Dunning (1966) con el concepto de equilibrio de tensiones. Tales actividades aparecen en el estado actual deportivo con un alto grado de institucionalización y detalle. Con

7 Como indican Lagardera y Lavega:"La estructura de un juego es como la partitura de una sinfonía. Sus notas están ya escritas, las acciones precondicionadas, ahora bien, cada músico o cada jugador hará gala de mayor o menor habilidad, precisión o fortuna a la hora de emitir cada una de las diferentes notas o de llevar a cabo diferentes acciones" (2003, p. 55).

8 Tal falta de historicidad hace que a veces Parlebas utilice supuestos funcionalistas a la hora de explicar tendencias sociales en vez de proceder justo al contrario y explicar la función mediante el estudio histórico. Así por ejemplo se pregunta: “¿Cúal puede ser la función social de los efectos perversos lúdicos?" (Parlebas, 2001, p. 97) o llega a interpretar de forma grosera la teoría del proceso de civilización de Elias cuando afirma que "Este sociólogo defiende la idea central de que una de las funciones básicas del deporte es permitir al estado-nación controlar o incluso monopolizar el derecho a la violencia física" (Parlebas, 2001, p. 152). 
esto cabe decir que las reglas que se establecen acotan los patrones recurrentes pero no deben entenderse como leyes que dictan el movimiento de unos átomos o, en este caso, de participantes con cierta capacidad de variación debido a su condición de seres racionales.

La praxiología podría resistir sin mucho problema esta parte de la crítica historicista, la referida a los cambios entendidos desde una visión macroscópica y de larga duración, ya que simplemente se desentiende de ella: no contempla cómo se producen los cambios porque tal cometido corresponde al estudio de la lógica externa (se dan fuera de la actividad, siendo esta siempre un reflejo de las condiciones sociales). La praxiología tan solo se limita a decir que, cuando hay ciertas reglas, hay cierta lógica interna asociada a ellas.

(ii) Sin embargo, la praxiología no puede resistir la crítica de la temporalidad si atendemos justamente al modo en el cual las actividades se van transmitiendo de unas personas a otras gracias a la producción/reproducción de las mismas cada vez que se ponen en juego, cada vez que se generan cursos de acción. Esto va a ser fundamental además para entender el modo equivocado en que la praxiología concibe la capacidad de agencia de los participantes, algo que vamos a desarrollar en el siguiente apartado. Lo único con lo que contamos en la praxiología es con una estructura que atiende a la lógica interna del juego y que es subyacente a las acciones desarrolladas por los actores que aparecen como meros soportes o transmisores de la misma. La continuidad del juego como tal parece deberse a esa estructura profunda que se va perpetuando a lo largo de las acciones de los jugadores, consideradas como epifenómenos de la lógica interna. Considero que esta forma de concebir la transmisión de lo social, la reproducción del juego, se desentiende completamente de cómo ocurre tal fenómeno en realidad. Cuando una persona se inicia en la práctica de un juego o deporte, lo primero que hace no es leer las reglas del juego -saber las reglas del juego no es saber jugar- para entenderlo (esto tampoco lo afirma la praxiología). Aprende jugando, imitando a los demás implicados en el juego. Es decir, imita patrones que le informan sobre el sentido común de lo que ahí se hace, sobre lo que allí se considera normal y apropiado y así seguirá desarrollando sus acciones más o menos dentro de los límites de la normalidad del juego. Pero atención: no es que, como afirma la praxiología, vaya adquiriendo la estructura de la lógica interna (esta solo existe para el investigador externo distanciado ${ }^{9}$ sino que va adquiriendo patrones de sentido común que implican que en cada nueva práctica deban volverse a generar secuencias normales si queremos mantener el juego, existiendo siempre la capacidad de producir variaciones y existiendo la capacidad extrema de romper el juego. Esta dinámica, que podríamos denominar de estructuración, ${ }^{10}$ es muy diferente a la que se basa en la regularidad de una estructura subyacente que los agentes ni siquiera son capaces de percibir. La regularidad en la estructuración proviene de la imitación de lo normal (no de la interiorización de la norma o la estructura profunda), que los actores siempre tienen que actuar en cada nueva situación si pretenden continuar con el juego. Tal imitación -que es siempre y hasta cierto punto innovativa- remite a la adquisición de un sentido práctico para desenvolverse, lo que implica cierta laxitud y variación ${ }^{11}$ en la forma de llevar a cabo las acciones de juego. Para utilizar una metáfora visual, la diferencia estriba en que, mientras que la praxiología trata de establecer la regularidad de la práctica mediante la concepción de una red o una malla interna ajena a los jugadores, en la estructuración se considera una malla en continua formación, como un telar que van tejiendo los actores en sus actividades mediante patrones que muestran regularidad porque se basan principalmente en la imitación pero que son capaces de introducir cambios en los mismos. Desde esta perspectiva, la idea de dinámica y cambio puede ser abordada de un modo menos forzado y más adecuado a cómo lo hace la praxiología, que se desentiende de la cuestión diciendo simplemente que esos fenómenos son algo externo.

\section{Falta de agencia de los participantes}

Como veíamos, el núcleo central del enfoque parlebasiano se formaba alrededor de una estructura

\footnotetext{
9 El error consiste en dar a tales leyes o procesos un carácter "óntico", considerar que "tienen existencia por sí mismos aunque se trate de creaciones humanas" (Lagardera \& Lavega, 2003, p. 22). Esto implica sin duda confundir la dimensión metodológica con la ontológica. Estoy de acuerdo en decir que se va a acotar el terreno de estudio a ese tipo de reglas pero estoy en desacuerdo en que se consideren esas reglas como separadas de la interacción de los seres humanos y que por tanto tienen una dimensión óntica. Este problema praxiológico asociado a su concepción realista es abordado en profundidad por Sánchez (1997).

10 Ver Giddens (2003) para la gran diferencia de concepción entre estructura y estructuración y las implicaciones que esto tiene sobre la capacidad de agencia de los actores sociales.

11 Como diría Bourdieu (1996), esta actividad se refiere más al seguimiento de estrategias prácticas que de reglas.
} 
subyacente a la práctica, atemporal, definida por su lógica interna. Así, la forma de analizar la capacidad de agencia o acción de los participantes debe estar en consonancia con esa idea fundadora. Es por eso que Parlebas (2001, p. 454) se apoya principalmente en la figura del actor racional de la teoría de juegos, que comparte con el estructuralismo la suposición de la categoría tiempo como algo "inesencial" (Osborne \& Rubinstein, 1994). La trama es la siguiente: una actividad ludodeportiva contiene en sí cierta lógica interna que ofrece a los participantes una serie de jugadas posibles a las cuáles esos se enfrentan como si fueran problemas separados a resolver. La forma de confrontar tales jugadas es siempre -siguiendo la teoría de juegos- de tipo estratégico, ${ }^{12}$ situación en la cual las decisiones tomadas deben tener en cuenta que el otro tiene información sobre lo que puedo saber y viceversa con lo que yo sé que tú sabes que yo sé, etc. y la previsión de tales cadenas reflexivas es vital para decidir ciertas acciones -de forma racional- y no otras. A modo de evitar concebir las actividades físico-deportivas como una simple confrontación de intelectos (como los juegos de cartas o el ajedrez), Parlebas (2001, p. 457) decide especificar una teoría de juegos deportivos en la cual las acciones corporeizadas tengan plena presencia y para ello introduce (siguiendo a la semiología) el concepto de interacción semiotriz: para tomar decisiones es fundamental poder codificar y descodificar los mensajes que están ocurriendo en las jugadas. La jugada prototípica para el enfoque de Parlebas es la finta ${ }^{13}$-tipo de acción en la que el ejecutor tiene que codificar un mensaje de forma estratégica- la cual recoge en sí todo el esquema de la agencia: los agentes implicados perciben ciertos signos, los descodifican y obtienen varias opciones entre las cuales elegir. Para llevar a cabo la elección se tiene siempre en cuenta que el otro es sensible a nuestras intenciones y acciones y por eso se elegirá cierta opción realizada (codificada) de cierto modo para que el resultado (superar mediante regate a un contrario, conseguir dar un pase a un compa- ñero) sea óptimo para nuestro interés y pésimo para el del contrario.

Pues bien, podemos considerar que tal esquema de actuación de los jugadores es inadecuado y que sigue sin hacer justicia a la temporalidad propia de los cursos de acción, introduciendo una forma de racionalidad teóri$\mathrm{ca}^{14}$ en una situación en la cual es fundamental un tipo de racionalidad práctica o en acción. ${ }^{15}$ Para demostrarlo me propongo a continuación centrar el análisis en lo que podemos denominar como sentido de juego (Bourdieu, 1991) asociado a los distintos niveles de maestría.

El concepto de nivel de maestría es capaz de poner en relación la temporalidad específica de la práctica con el paso del tiempo -historicidad- asociado al proceso de aprendizaje; la forma de obtener maestría está asociada a la práctica continuada y recurrente de una actividad. El nivel de maestría introduce además una asimetría entre los jugadores, rompiendo así esa concepción ideal parlebasiana de que todos los jugadores se enfrentan a las mismas situaciones en el campo de juego, dando simplemente distintas soluciones. En realidad ocurre que, ya de por sí, jugadores con distinto nivel de maestría desarrollan sus acciones en horizontes perceptivoscognitivos distintos; si bien jugadores de muy distinto nivel se encuentran realizando juntos una actividad, la forma de concebir, de relacionarse con la misma varía mucho según el nivel de práctica, según su sentido de juego. Está claro que a medida que una persona practica una actividad va ganando nivel de maestría que la hace percibir-actuar dentro de la actividad de un modo distinto a como lo hacía; digamos que de un modo más experto, más ajustado a las soluciones que demanda la actividad motriz. Es este nivel de maestría (que varía en cierta medida según las características personales de cada uno) el que nos refiere a la temporalidad propia de un agente encarnado -situado en una situación motriz en la cual tiene que percibir y actuar- con un cierto sentido de juego adquirido que le permite ajustarse de manera inmediata (más cuanto más experto sea) a las demandas

12 He decidido tomar el análisis de las situaciones en las cuales hay compañeros y contrarios ya que, en el esquema parlebasiano, representan el tipo de actividades con mayor complejidad, siendo las realizadas con incertidumbre pero en solitario situaciones fácilmente explicables a partir de las primeras.

13 Jugada que por otra parte, si bien tiene relevancia en el juego, no es la acción más repetida ni siempre es deseada debido a que la compleja codificación puede engañar tanto al contrario como a los compañeros y muchas veces se prefieren acciones con "intenciones claras" pero aún así de gran eficacia.

14 Teórica significa distanciada, que es la forma en la cual Parlebas concibe el análisis del juego: flujo que puede descomponerse en partes, en jugadas aisladas, ideales para una situación de laboratorio praxiológico. El propio Parlebas trata de paliar tales deficiencias con conceptos tan confusos metodológicamente como preacción (2001, p. 358) o prepercepción (2001, p. 248).

15 Ver Sánchez (2009a) para un análisis en profundidad sobre las diferencias entre la racionalidad teórica y práctica en la realización de las prácticas físico-deportivas. 
del juego. Este planteamiento es muy distinto al que hacía la praxiología, donde los agentes se encuentran con varias opciones ante sí, tomando decisiones de modo estratégico (distanciado respecto a la urgencia de la acción). Es el sentido de juego adquirido el que hace coincidir de manera simultánea la percepción y el proyecto de acción adecuado, "lo que toca en ese momento", la buena jugada, ya sea un regate, una orientación, una finta, un pase. Que exista ya en la percepción ese proyecto de acción, ${ }^{16}$ esa proyección hacia el hacer no implica que finalmente se haga (ahí influye por ejemplo la afectividad personal de cada uno, asunción de riesgos, etc.) pero sí que existe ese sentido de juego asociado a un nivel de maestría que por tanto contiene en sí cierto carácter objetivo; no es por tanto ese nivel simplemente, como diría Parlebas (2001, p. 251), algo subjetivo y por tanto desdeñable desde la óptica de la lógica interna. De hecho, Parlebas decide de manera arbitraria que debemos presuponer la situación ideal de unos agentes que ya son expertos en la práctica que realizan:

... en una clasificación de los modelos de situaciones motrices (esquí, salto de altura, vela...), conviene adoptar la perspectiva del practicante experimentado para neutralizar al máximo el parámetro subjetividad -impertinente en este caso- en beneficio de los elementos objetivos de la situación (entorno estable y sin imprevistos o por el contrario, cambiante y no previsible del todo); dicha perspectiva equivale, lisa y llanamente, a contemplar el deporte tal y como se practica de hecho en las situaciones institucionales habituales (2003, pp. 251-252).

Así, para Parlebas, la única asimetría y variedad en los comportamientos se da gracias a lo subjetivo, a la personalidad de cada uno de los jugadores, ${ }^{17}$ pero se obvia la cuestión objetiva que nosotros hemos planteado acerca del nivel de maestría y que de ningún modo se puede desdeñar como parte no integrante y no fundamental del tipo de actividad que estamos analizando. Procediendo de este modo, Parlebas consigue blindar su análisis, centrado alrededor de la lógica interna. Ahora bien, podríamos preguntar ¿no implica esto un error de base a la hora de informar una práctica pedagógica? ¿Qué valor puede aportar un análisis de una situación en la que se da por hecho que los sujetos son expertos cuando en la mayoría de los casos encontramos sujetos en distintos niveles de aprendizaje y muchos de los cuales pueden considerarse principiantes ante ciertas situaciones?

Para que el análisis sea pertinente no podemos nunca dejar fuera del contexto el nivel de maestría de los participantes. Este está informando verdaderamente de la temporalidad propia de las actividades tal y como las vamos a encontrar en cada situación. No podemos olvidar que, por ejemplo, referido al criterio de incertidumbre, una barra de equilibrios puede ser un entorno extremadamente salvaje para un principiante o que hacer un rally para un piloto de carreras a $100 \mathrm{~km} / \mathrm{h}$ puede ser un simple reconocimiento mientras que para un conductor normal podría ser una experiencia a la vez muy excitante y atemorizante. No basta simplemente con decir que tal variación en la incertidumbre no se debe a la tarea (lo interno) sino a las características de los participantes y que por tanto no es pertinente para el estudio de la praxiología sino de la psicología. Debe introducirse en el análisis los niveles de maestría que den cuenta de un sentido de juego asociado a cada nivel, el cual afecta determinantemente a cómo se concibe la actividad por cada participante.

Estos ejemplos nos van a remitir directamente al último apartado de este trabajo, aquel en el que mostramos de forma clara las limitaciones de aplicación de la praxiología a otros ámbitos.

\section{Limitaciones en la aplicación de la praxiología motriz}

Hemos visto como todas las dificultades de adecuación de la praxiología motriz a su objeto de estudio provenían de un punto de partida que consistía en la separación de la lógica interna de la externa, privilegiando el análisis de la primera. Esto generaba la imposibilidad del tratamiento de una actividad eminentemente práctica (las actividades físico-deportivas) desde un enfoque eminentemente distanciado o teórico. Las únicas regularidades que estaba dispuesta a conceder la praxiología eran las de la lógica interna, en estrecha relación con las

16 Lo que Gibson (1986) denominaba con el término affordance o lo que yo (Sánchez, 2010) denominaba, desde una perspectiva enactiva, como oportunidad táctica.

17 Como indican Lagardera y Lavega: "Lorenzo, el más atrevido y arriesgado, siempre quiere ir en busca del balón; Marta, mucho más calculadora, opta por asegurar sus acciones motrices, sin dejar de mirar atentamente a sus adversarios y compañeros; Carlos, más inseguro y dubitativo, es el primero en no saber anticiparse a un contrario despistado y le eliminan [...] Cada uno de estos jugadores lee, descifra e interpreta la gramática del juego de modo distinto, realizando cada una de las acciones motrices con características muy personales y propias" (2003, p. 197). 
normas que regían las actividades ludodeportivas. No era capaz de ver que tales elementos conformaban leyes que actuaban como límites de unos patrones recurrentes (los propios de los cursos de acción) que quedaban sin estudiar y que eran básicos para una adecuada comprensión de la temporalidad de la práctica y de la capacidad de agencia de los participantes.

Pretendemos en este último apartado mostrar cómo las aplicaciones de la praxiología motriz -la vuelta desde la lógica interna hacia la lógica externa- encuentran las dificultades propias debidas a ese punto de partida particular en el que se cimienta esta disciplina científica.

Una limitación seria que encuentra la praxiología para servir de base a una buena aplicación pedagógica es que obliga a creer -como un acto de fe- en lo que consideramos la magia de las prácticas: basta con identificar la lógica interna de unas actividades -por ejemplo, como cooperativa o de oposición- para que podamos planificar programas educativos con determinados fines. Este modo de proceder, basado en el ideal de obtener una pedagogía informada por la práctica científica racional, genera en los praxiólogos una serie de expectativas prometedoras a partir del esfuerzo del descifrado de las gramáticas lúdicas por las cuales:

podríamos saber con certidumbre la cadena de acciones lógicas que pueden generarse en un determinado juego, y sabríamos así de sus posibilidades y limitaciones práxicas. Qué prácticas generan violencia y hasta qué grado, qué prácticas son más cooperativas que otras o cuáles promueven la individualidad o la colectividad, todo ello debidamente contrastado (Lagardera \& Burgués, 2003, p. 34).

Sin embargo, a pesar de la buena intención de la propuesta, la considero equivocada. El hecho de fijarnos solo en la lógica interna como criterio de diseño pedagógico sería análogo al caso de aquel que va al médico porque le duele la espalda y el colegiado simplemente le responde que haga natación y se aleje de las pesas. La respuesta del médico (y del praxiólogo) se refiere a tipos ideales de actividad, no a cómo se produce la actividad en situación real. Digo esto porque, precisamente a lo largo de mi estudio de tesis (Sánchez, 2006), constaté, no solo que artes marciales como el aikido podían ser fantásticas para el entendi- miento y la educación sobre la violencia (algo que muchos maestros de artes marciales señalan, si bien no siempre son escuchados) sino que el propio boxeo podía ser una herramienta perfecta para ello siempre que se hicieran unos programas adecuados -sin necesidad de variar su lógica interna- para tales efectos. Por el contrario, desde el punto de partida del análisis praxiológico, los deportes de combate ${ }^{18}$ en general, y el boxeo en particular, serían una de las últimas actividades que podrían ser propuestas para fomentar la no violencia, el respeto hacia el otro y la superación mutua.

La priorización romantizada de Parlebas de la utilización de los juegos populares respecto al deporte (Parlebas, 2001, pp. 269, 289) como modo de instauración de modelos no pertenecientes al duelo y la oposición directa -tal y como se da en los deportes actuales- no sería capaz por sí sola de contestar a preguntas como: ¿de qué forma saber por ejemplo que en un juego tradicional de todos contra todos, lejos de establecer un equilibrio perfecto entre cooperación y oposición, no pueda marginarse siempre al menos hábil que siempre carga con el peor rol del juego? ¿No eran los deportes de las Public Schools inglesas duelos entre equipos como los de ahora (misma lógica interna) y sin embargo no promovían ganar a toda costa sino el concepto de fair play?

Por tanto, desde el análisis de la lógica interna, esas conclusiones distan mucho de ser claras y se necesita una observación empírica minuciosa de las actividades para corroborarlo. Me consta que los praxiólogos estarían de acuerdo en esa comprobación o contrastación empírica pero entonces ¿dónde queda la prioridad de la lógica interna en el diseño pedagógico? La aceptación de tal comprobación, ¿no está privilegiando la observación propia de los cursos de acción que en un principio se pretendía desechar o presentar como algo inesencial?

Todos estos ejemplos muestran la inadecuación en la separación de la lógica interna de la externa, algo que tan solo es posible de modo ideal o analítico pero que no puede realizarse al volver sobre las prácticas; es así como la cuestión de análisis praxiológico no puede separarse de la pedagogía y la didáctica (condiciones socioculturales de transmisión y procedimientos de enseñanza) o de las peculiaridades sociales de los practicantes que introducirán su propio ethos en la actividad que realizan.

18 Según Parlebas: "La lógica interna de los combates singulares es una lógica de destrucción, real o simbólica, del cuerpo del adversario. El sistema de victorias y puntuaciones que sanciona el asalto se basa sin ambigüedades en el testimonio directo de esa dominación corporal: victoria por el número de "toques", por "caída", por "estrangulamiento", por "proyección", por poner fuera de combate, por tirar la toalla o por knock out" (Parlebas, 2003, p. 206). 


\section{Coda final: volviendo sobre los cursos de acción}

A lo largo del presente artículo se han presentado una serie de posibles deficiencias o limitaciones tanto en el análisis como en la aplicación de la praxiología motriz. Para concluir, quiero señalar brevemente una posible vía de solución o compensación a ese fenómeno: el estudio de la estructuración de los cursos de acción, tal y como realiza la etnometodología (Garfinkel, 2006; Garfinkel \& Sacks, 1986; Izquierdo, 2003). Esto ayudaría a resolver las limitaciones del enfoque praxiológico, tanto en el análisis de las actividades deportivas (Fele, 1997; Sánchez, 2008, 2009b) como en sus aplicaciones en el ámbito del diseño pedagógico o del rendimiento.

Atendiendo a cómo se producen esos patrones recurrentes que caracterizan la práctica deportiva (no atendiendo a las normas ideales de los universales o a las reglas del juego que simplemente acotan los patrones de acción, no son lo mismo que ellos) sería posible recuperar $a$ ) la temporalidad propia de la actividad, que se produce dentro de una urgencia práctica y $b$ ) la capacidad de agencia de los participantes de esas actividades, el sentido de juego del jugador (Bourdieu, 1991), forma encarnada de pensamiento en acción que está asociada a unos niveles de maestría objetivables. ${ }^{19}$

El estudio de tales cursos de acción permitiría además ahondar más en cuestiones tales como el proceso de adquisición del sentido de juego, la creatividad e innovación motriz, la diferencia -sincrónica y diacrónica- en estilos y sistemas de juego dentro de una misma actividad o el diseño de actividades cuya aplicación educativa transmitiera los valores pretendidos, etc.

\section{Referencias}

Bourdieu, P. (1991). El sentido práctico. Madrid: Taurus.

Bourdieu, P. (1996). Cosas dichas. Barcelona: Gedisa.

De Saussure, F. (2000). Course in General Lingüistics. En L. Burke,

T. Crowley, \& A. Girving (Eds.), The Routledge Language and Cultural Theory Reader. London: Routledge.
Elias, N. \& Dunning, E. (1966). Dynamics of Group Sports with Special Reference to Football. British Journal of Sociology, XVII(4), 388402 doi:10.2307/589186

Fele, G. (1997). Sociology of Action: Ethnomethodological interpretations of soccer. En Analisi della conversazione e prospettive di ricerca in etnometodologia. Actas del congreso internacional de Urbino, 11-13 julio 1994, pp. 43-58.

Garfinkel, H. (2006). Estudios en etnometodología. Barcelona: Anthropos.

Garfinkel, H. \& Sacks, H. (1986). On formal structures of practical actions. En H. Garfinkel (Ed.), Ethnomethodological Studies of Work (pp. 160-194). London: Routledge.

Gibson, J. J. (1986). An Ecological Approach to Visual Perception. New Jersey: LEA.

Giddens, A. (2003). La constitución de la sociedad. Bases para la teoría de la estructuración. Buenos Aires: Amorrortu.

Izquierdo, J. (2003). La tercera juventud de Harold Garfinkel: una nueva invitación a la etnometodología. ANDULI (3), 47-66.

Lagardera, F. (1993). Contribución de los estudios praxiológicos a una teoría general de las actividades físico-recreativas. Apunts. Educación Física y Deportes (32), 10-17.

Lagardera, F. \& Lavega, P. (2003). Introducción a la praxiología motriz. Barcelona: Paidotribo.

Osborne, M. J. \& Rubinstein, A. (1994). A Course in Game Theory. Boston: MIT Press.

Parlebas, P. (1987). Perspectivas para una educación física moderna. Málaga. Unisport.

Parlebas, P. (2001). Léxico de praxiología motriz. Barcelona: Paidotribo.

Parlebas, P. (2003). Elementos de Sociología del Deporte. Málaga: IDA.

Sánchez, R. (2006). Paradigma cultural y violencia en la sociedad española: el caso de los deportes de combate en la Comunidad de Madrid (Tesis doctoral no publicada). Universidad Politécnica de Madrid: Madrid.

Sánchez, R. (2008). Análisis etnometodológico sobre el dinamismo del habitus en Bourdieu y Elias dentro del desarrollo de actividades corporales. Reis: Revista española de investigaciones sociológicas (124), 209-231

Sánchez, R. (2009a). ¿Qué significa pensar en acción? Apunts. Educación Física y Deportes (98), 88-96.

Sánchez, R (2009b). Ethnomethodological and Conversational Analysis of Alley Oop. Ponencia presentada en el programa de doctorado de Sociología, Universidad de Manchester, Inglaterra.

Sánchez, R. (2010). La propuesta inactiva en las actividades físicodeportivas. Artículo inédito.

Serrano, J. A. (1997). La praxeología motriz: ¿disciplina autónoma o paradigma de la educación física? En Consejo Superior de Deportes, Investigación epistemológica: el campo disciplinar en educación física. Serie ICd, n. ${ }^{\circ} 16$ (pp. 68-118). Madrid: Ministerio de Educación y Cultura - Consejo Superior de Deportes.

Wacquant, L. (2004). Entre las cuerdas. Cuadernos de aprendiz de boxeador. Madrid. Alianza.

19 En este doble sentido de temporalidad y agencia, sería especialmente útil realizar una lectura etnometodológica del concepto de habitus en Bourdieu (Sánchez, 2008) que, por falta de espacio no desarrollamos aquí. Así mismo, la utilización ventajosa del concepto de habitus de Bourdieu -mal entendido por Parlebas (2001, p. 242 y ss., 2003, pp. 91, 229-232)- ofrecería en sí una llave para la difícil solución a la relación entre la lógica interna de la actividad y el ámbito sociocultural (la lógica externa). Las prácticas deportivas nunca se producen en el vacío (como parece ocurrir en los análisis ideales parlebasianos); siempre aparecen encarnadas en agentes pertenecientes a determinados ámbitos socioculturales, con ciertos valores asociados a la práctica. Para un magnífico estudio en este sentido, aplicado a las actividades deportivas, ver la obra de Wacquant (2004) sobre el universo pugilístico en Chicago. 